\title{
Adaptabilidade na produção de massa verde e grãos de genótipos de milho no Tocantins ${ }^{1}$
}

\author{
Adaptability in fresh weight and grain production in maize genotypes in Tocantins, \\ Brazil
}

\author{
Edmar Vinícius de Carvalho²*, Flávio Sérgio Afférri³ ${ }^{3}$ Joênes Muci Pelúzio ${ }^{4}$, Weder Ferreira dos Santos ${ }^{4}$ e Sílvio \\ José Bicudo 5
}

\begin{abstract}
RESUMO - Condições distintas de cultivo fazem com que a resposta dos genótipos seja diferente em cada situação. Para amenizar o efeito desta interação são realizadas análises de adaptabilidade e estabilidade, que auxiliam na escolha dos genótipos. Porém, muitas vezes, um genótipo apresenta diversas finalidades, causando problemas ao agricultor em algumas situações e, o uso de genótipos específicos, poderia ser uma solução. O objetivo desta pesquisa foi estudar a adaptabilidade e estabilidade de genótipos de milho na região Centro-Sul do Estado do Tocantins, e classificá-los, quanto a tendência da finalidade produtiva: grãos ou massa verde. Foram realizados oito experimentos em dois municípios do Tocantins na entressafra 2010 e na safra 2010/2011, sendo avaliados 16 genótipos de milho. Avaliou-se a massa verde total da planta e a produção de grãos (em g planta ${ }^{-1}$ ), as quais foram usadas na análise de adaptabilidade e estabilidade e, posteriormente buscou-se classificar a tendência da finalidade produtiva dos genótipos. Os genótipos P09, P12, P10, H02 e H01 apresentaram classificação do coeficiente de regressão superior na produção de grãos em relação à massa verde total da planta, acontecendo o contrário com os genótipos P02 e P01. O genótipo H01, quanto à produção de grãos, foi adaptado a ambientes favoráveis e apresentou tendência da finalidade produtiva para esta característica. Ao contrário dos genótipos $\mathrm{P} 08$ e P02, que foram adaptados a ambos ambientes e a ambientes favoráveis, respectivamente, quanto à massa verde total da planta e, obtiveram tendência da finalidade produtiva para esta característica.
\end{abstract}

Palavras-chave: Milho-melhoramento genético. Interação genótipo-ambiente. Adubação orgânica.

\begin{abstract}
Different growth conditions give genotypes a different response to each situation. To reduce the effect of this interaction, analyses of stability and adaptability are undertaken, which assist in choosing the genotypes. However, often a genotype can have a variety of purposes, causing problems to farmers in some situations, and the use of specific genotypes could be a solution. The objective of this research was to study the adaptability and stability of maize genotypes in the South Central region of the state of Tocantins, Brazil, and to classify them according to trends in productivity goals: grain or green weight. Eight experiments were conducted in two towns in Tocantins in the 2010 off-season and the 2010/2011 season, in which 16 maize genotypes were evaluated. The total plant green weight and grain production $\left(\mathrm{g} \mathrm{plant}^{-1}\right)$ were evaluated and then used in the analysis of stability and adaptability. Later it was sought to classify the trends in productivity goals for the genotypes. The genotypes P09, P12, P10, H02 and H01 displayed a superior classification of the regression coefficient for grain production compared to total plant green weight, with the opposite happening in the P02 and P01 genotypes. Genotype $\mathrm{H} 01$, as regards grain production, was adapted for favourable environments and displayed a tendency for this characteristic as a productive goal. Unlike the P08 and P02 genotypes that were adapted for both environments or for favourable environments respectively, as regards total plant green weight, and show a trend in productive goals for this characteristic.
\end{abstract}

Key words: Maize-breeding. Genotype-environment interaction. Organic Fertilisation.

\footnotetext{
*Autor para correspondência

'Recebido para publicação em 22/05/2012; aprovado em 01/05/2014

Parte de Dissertação de Mestrado do primeiro autor

${ }^{2}$ Programa de Pós-Graduação em Produção Vegetal, Universidade Federal do Tocantins, Rua, Badejós, Lote 7, Chácaras 69/72, Zona Rural, Gurupi-TO, Brasil, 77.402-970, carvalho.ev@uft.edu.br

${ }^{3}$ Universidade Federal de São Carlos, Buri-SP, Brasil, flavioafferri@gmail.com

${ }^{4}$ Departamento de Engenharia Agrícola, Universidade Federal do Tocantins, Palmas-TO, Brasil, joenesp@uft.edu.br; eng.agricola.weder@gmail.com

5Faculdade de Ciências Agronômicas, Universidade Estadual Paulista “Júlio de Mesquita Filho", Jaboticabal-SP, Brasil, sjbicudo@fca.unesp.br
} 


\section{INTRODUÇÃO}

Conceito primordial no melhoramento genético de plantas, a interação entre genótipo e ambiente é de suma importância para os melhoristas, pois sua interpretação é de que cada genótipo pode responder de forma diferente com a mudança do ambiente (SCAPIM et al., 2010). Como ambientes distintos, podem-se considerar as diferentes condições de: solo e clima; local; safra; nível de tecnologia (SCAPIM et al., 2000); adubação de semeadura e cobertura (RIOS et al., 2009); dentre outros fatores.

Para amenizar o efeito desta interação (SILVA; DUARTE, 2006), são feitas análises de adaptabilidade e estabilidade (FARIA et al., 2010), que auxiliam na escolha dos genótipos adaptados a cada condição ou região, que sejam estáveis e também produtivos (SILVA; DUARTE, 2006). Dentre as inúmeras metodologias de análise de adaptabilidadee estabilidade, merece destaque a proposta por Eberhart e Russel (FARIA et al., 2010), a qual se baseia na análise de regressão linear simples (SCAPIM et al., 2000), considerando genótipo ideal aquele que apresenta alta previsibilidade, aumento de produtividade com a melhora da condição ambiental e alto potencial produtivo (EBERHART; RUSSEL, 1966), tendo a simplicidade de interpretação dos parâmetros gerados grande importância na sua ampla utilização pelos melhoristas (OLIVEIRA et al., 2006).

Outra informação na escolha do genótipo é a finalidade de produção. No Brasil, ente os genótipos de milho disponíveis, menos de $1 \%$ são indicados especificamente para a produção de silagem de planta inteira ou milho verde; e mais de $98 \%$ das cultivares são indicadas para produção de grãos, sendo que desse total, 59\% são indicadas somente para a produção de grãos e $41 \%$ para a produção de grãos ou silagem (CENTRO NACIONAL DE PESQUISA DE MILHO E SORGO, 2011).

Isto condiciona o produtor que pretende produzir silagem de milho (oriunda da massa verde total colhida do milho), optar por genótipo de dupla aptidão, podendo causar a seguinte situação: semeadura de área de milho objetivando produção de silagem e colheita de grãos. Implicando, no aumento dos custos de produção ou redução de produtividade, pois a redução da primeira e o aumento da segunda podem ser atingidos através do conhecimento minucioso da atividade planejada (PARIZ et al., 2009). No caso em questão, é necessário ressaltar as diferenças entre a condução da lavoura de milho para grãos e silagem, onde no segundo caso são necessários aumento da densidade populacional (SILVA, 1991) e adubação (VALENTE et al., 1991), aumentando os custos de produção. Tentando minimizar estes riscos, o desenvolvimento de genótipos específicos para cada situação pode ser mais vantajoso (SCHAEFER; SHEAFFER; BERNARDO, 2011), tanto na finalidade de uso (MORENO-GONZÁLEZ et al., 2000) como para público-alvo (SANDOYA et al., 2010).
Com relação à busca de genótipos voltados para a produção de silagem, os mesmos devem possuir produção de massa verde acima de $30 \mathrm{t} \mathrm{ha}^{-1}$ para serem economicamente viáveis nesta finalidade (VALENTE et al., 1991), e acima de 50 tha $^{-1}$ para serem considerados como os de boa produção (BATES , 2009); além disso, boa relação entre Massa Verde/ grãos e qualidade da silagem (SILVA, 1991).

Diante do exposto, o objetivo desta pesquisa foi estudar a adaptabilidade e a estabilidade de genótipos de milho na região centro-sul do Estado do Tocantins, e classificá-los, quanto à tendência da finalidade produtiva: grãos ou massa verde.

\section{MATERIAL E MÉTODOS}

Foram avaliados 16 genótipos de milho, sendo 12 populações experimentais desenvolvidas por top crosses de linhagens com testador base genética ampla, dois híbridos simples experimentais obtidos por meio de cruzamentos de linhagens $\mathrm{S}_{5} \mathrm{e}$, duas testemunhas comerciais, sendo, um híbrido duplo (T02) e uma variedade (T01).

Os municípios em que foram conduzidos os experimentos no Estado do Tocantins apresentam as seguintes localizações geográficas e características de solo: 1) Gurupi-TO, $11^{\circ} 43^{\prime} \mathrm{S}, 49^{\circ} 15^{\prime} \mathrm{W}$, altitude de $287 \mathrm{~m}$, em um Latossolo Vermelho-Amarelo com textura Arenosa distrófico; 2) Palmas-TO, $10^{\circ} 10^{\prime} \mathrm{S}, 48^{\circ} 21^{\prime} \mathrm{W}$, altitude de $212 \mathrm{~m}$, em um Latosso Vermelho-Amarelo com textura Arenosa distrófico. $\mathrm{O}$ solo de Gurupi-TO apresentou as seguintes características físico-químicas: Matéria Orgânica $(\mathrm{MO})=0,4 \% ; \mathrm{pH}\left(\mathrm{H}_{2} \mathrm{O}\right)$ $=5,6 ; \mathrm{P}(\mathrm{Mel})=4,8 \mathrm{ppm} ; \mathrm{K}^{+} ; \mathrm{Ca}^{2+} ; \mathrm{Mg}^{2+}$ e $\mathrm{H}+\mathrm{Al}=0,1$; 1,$2 ; 1,3 ; 3,4 \mathrm{cmol} \mathrm{dm}^{-3}$, respectivamente; $\mathrm{V}=42,2 \%$; e o de Palmas-TO: $\mathrm{MO}=0,6 \% ; \mathrm{pH}\left(\mathrm{CaCl}_{2}\right)=4,9 ; \mathrm{P}(\mathrm{Mel})=6 \mathrm{ppm}$; $\mathrm{K}^{+} ; \mathrm{Ca}^{2+} ; \mathrm{Mg}^{2+}$ e $\mathrm{H}+\mathrm{Al}=0,09 ; 1,04 ; 0,43 ; 3,13 \mathrm{cmol} \mathrm{dm}^{-3}$, respectivamente; $\mathrm{V}=33,3 \%$; O clima da região Centro-Sul do Tocantins é do tipo B1wA'a' úmido com moderada deficiência hídrica, segundo a classificação de Köppen.

Nesses municípios, oito experimentos foram conduzidos na entressafra de 2010 e na safra verão 2010/2011, os quais estão descritos na Tabela 01, para avaliação dos dezesseis genótipos de milho, propiciando aos genótipos ambientes distintos de cultivo.

O esterco bovino utilizado como adubação de semeadura foi aplicado 15 dias antes da semeadura no sulco de plantio nos experimentos III e IV, e seis dias antes da semeadura nos experimentos V e VI, sempre com a dose de $40 \mathrm{t} \mathrm{ha}^{-1}$, onde o esterco bovino apresentou as seguintes características: $\mathrm{MO}=10,8 \%$; $\mathrm{pH}\left(\mathrm{H}_{2} \mathrm{O}\right)=7,3 ; \mathrm{P}(\mathrm{Mel})=720 \mathrm{ppm} ; \mathrm{K}^{+} ; \mathrm{Ca}^{2+} ; \mathrm{Mg}^{2+} \mathrm{e}$ $\mathrm{H}+\mathrm{Al}=24,9 ; 7,9 ; 8,2 ; 2,0 \mathrm{cmol} \mathrm{dm}^{-3}$, respectivamente; $\mathrm{V}=91,5 \%$. 
Tabela 1 - Caracterização de oito experimentos de avaliação de 16 genótipos de milho na região Centro-Sul do Estado do Tocantins

\begin{tabular}{|c|c|c|c|c|}
\hline Experimento & Município & Data de semeadura & Adubação de Semeadura & Adubação de Cobertura \\
\hline I & Gurupi & 06 jul. $2010^{1}$ & $500 \mathrm{~kg}$ ha $05-25-15(\mathrm{NPK})$ & $0 \mathrm{~kg} \mathrm{ha}^{-1} \mathrm{~N}$ \\
\hline II & Gurupi & 06 jul. 2010 & $500 \mathrm{~kg}$ ha $05-25-15$ (NPK) & $125 \mathrm{~kg} \mathrm{ha}^{-1} \mathrm{~N}$ \\
\hline III & Gurupi & 06 jul. 2010 & 40 tha (Esterco Bovino) & $0 \mathrm{~kg} \mathrm{ha}^{-1} \mathrm{~N}$ \\
\hline IV & Gurupi & 06 jul. 2010 & 40 t ha (Esterco Bovino) & $125 \mathrm{~kg} \mathrm{ha}^{-1} \mathrm{~N}$ \\
\hline $\mathrm{V}$ & Gurupi & $16 \mathrm{dez} .2010^{2}$ & 40 t ha (Esterco Bovino) & $100 \mathrm{~kg} \mathrm{ha}^{-1} \mathrm{~N}$ \\
\hline VI & Gurupi & 16 dez. 2010 & 40 t ha (Esterco Bovino) & $0 \mathrm{~kg} \mathrm{ha}^{-1} \mathrm{~N}$ \\
\hline VII & Palmas & 02 dez. 2010 & $500 \mathrm{~kg}$ ha $05-25-15$ (NPK) & $125 \mathrm{~kg} \mathrm{ha}^{-1} \mathrm{~N}$ \\
\hline VIII & Palmas & 02 dez. 2010 & $500 \mathrm{~kg}$ ha $05-25-15$ (NPK) & $0 \mathrm{~kg} \mathrm{ha}^{-1} \mathrm{~N}$ \\
\hline
\end{tabular}

${ }^{1}$ Referente a entressafra do ano de 2010; ${ }^{2}$ Referente a safra verão 2010/2011

Nos experimentos que receberam nitrogênio em cobertura (II, IV, V e VII), a adubação foi realizada quando as plantas estavam no estágio de quatro a seis folhas, utilizando uréia como fonte nitrogenada, na dose de $125 \mathrm{~kg} \mathrm{ha}^{-1}$ de N nos experimentos II, IV e VII, e na dose de $100 \mathrm{~kg} \mathrm{ha}^{-1} \mathrm{de}$ $\mathrm{N}$ no experimento $\mathrm{V}$. A irrigação foi utilizada somente nos experimentos I, II, III e IV (entressafra de 2010). Os demais tratos culturais usualmente aplicados em cultivo convencional da cultura do milho foram efetuados assim que se fizeram necessários, segundo Fancelli e Dourado Neto (2000).

Foi utilizado o delineamento de blocos completos ao acaso com 16 tratamentos e duas repetições, com parcela experimental constituída por duas fileiras centrais de 4,0 m de comprimento, espaçadas por 1,0 m, com estande ideal de 20 plantas por fileira.

As coletas de dados aconteceram em duas fases: a primeira no ponto de grãos farináceos, onde foi avaliada a produção de massa verde total da planta (massa verde) dos genótipos, colhendo-se três plantas por parcela, com os valores expressos em g planta $^{-1}$; e a segunda, no ponto de colheita de grãos, onde foi avaliada a produção de grãos (grãos) dos genótipos, colhendo-se espigas representativas da parcela, as quais foram colocadas para secar antes da debulha. Os valores de grãos foram expressos em g planta ${ }^{-1}$, corrigidos pela umidade (13\%).

Foi realizada a análise de adaptabilidade e estabilidade pela metodologia de Eberhart e Russel (1966), com auxilio do programa estatístico ESTABILIDADE - versão 3.0 (FERREIRA, 1998), em cada característica. A metodologia de Eberhart e Russell (1966) usa, na avaliação individual dos genótipos, a produtividade média do genótipo $\left(\mu_{\mathrm{i}}\right)$, o seu coeficiente de regressão $\left(\beta_{1}\right)$ e a variância dos desvios dessa regressão $\left(\sigma 2_{\mathrm{di}}\right)$.
Posteriormente, foram calculadas a Produção Relativa dos Genótipos (PR), (Equação 1) como forma de obtenção de um valor que represente o desempenho do genótipos em relação aos demais, e a Tendência da Finalidade Produtiva (TFP), (Equação 2), na busca de um parâmetro que indique, simultaneamente, em ambientes distintos, o potencial relativo de maior ênfase, entre produção de grãos ou massa verde:

$P R=P G_{n} / P G_{M}$

em que: $\mathrm{PR}=$ produção relativa do genótipo "n"; $\mathrm{PG}_{\mathrm{n}}=$ produção média do genótipo " $n$ " em todos os ambientes; $\mathrm{PG}_{\mathrm{M}}$, = produção média de todos os genótipos.

$\mathrm{TFP}=\left(\beta_{\mathrm{GR}} * \mathrm{PR}_{\mathrm{GR}}\right) /\left(\beta_{\mathrm{MV}} * \mathrm{PR}_{\mathrm{MV}}\right)$

em que: TFP = tendência da finalidade produtiva do genótipo " $n$ "; $\beta_{\mathrm{GR}}=$ coeficiente de regressão linear para produção de grãos; $\mathrm{PR}_{\mathrm{GR}}=$ produção relativa para produção de grãos; $\beta_{\mathrm{MV}}=$ coeficiente de regressão linear para produção de massa verde total da planta $\mathrm{e} ; \mathrm{PR}_{\mathrm{MV}}=$ produção relativa para produção de massa verde total da planta.

\section{RESULTADOS E DISCUSSÃO}

\section{Adaptabilidade e Estabilidade}

$\mathrm{Na}$ produção de grãos e massa verde foram constatados efeitos significativos da interação entre genótipo e experimento, demonstrando a resposta diferencial dos genótipos nos experimentos estudados 
(SCAPIM et al., 2010), justificando assim, a determinação da adaptabilidade e estabilidade (PELUZIO et al., 2005), para ambas as características.

Pelo método de Eberhart e Russel (1966) os ambientes são classificados como favoráveis (índice ambiental positivo) e desfavoráveis (índice ambiental negativo), em que, na produção de grãos os experimentos IV, V e VII foram classificados como favoráveis e, os demais como desfavoráveis. Na massa Verde, os ambientes favoráveis foram os quatro da entressafra mais o experimento V.

O parâmetro utilizado na avaliação da adaptabilidade dos genótipos pela metodologia de Eberhart e Russell (1966) é o coeficiente de regressão ( $\beta)$ e, o parâmetro de estabilidade, o desvio da regressão (Desv. Reg.), que indica a previsibilidade dos genótipos em relação à mudança do ambiente (RIOS et al., 2009).

$\mathrm{O}$ genótipo $\mathrm{H} 01$ apresentou coeficiente de regressão superior à unidade $(\beta>1)$ e desvio da regressão não significativo, o que demonstra a sua adaptação a ambientes favoráveis e previsibilidade de comportamento (SCAPIM et al., 2010), apresentando, ainda, produção de grãos acima da média, aproximadamente $142 \mathrm{~g} \mathrm{planta}^{-1}$ (Tabela 2). Assim, de acordo com Silva e Duarte (2006), que relatam que o objetivo destas análises é identificar genótipos que sejam adaptados, estáveis e produtivos, este genótipo foi o mais adequado nos ambientes favoráveis na produção de grãos.

Tabela 2 - Adaptabilidade ( $\beta$ ) e Estabilidade (Desv. Reg.) de 16 genótipos de milho em oito experimentos milho na região Centro-Sul do Estado do Tocantins

\begin{tabular}{lcccccc}
\hline \multirow{2}{*}{ Genótipo } & \multicolumn{1}{c}{ B } & Desv. Reg. & Média & $\beta$ & Desv. Reg. & Média \\
\cline { 2 - 6 } P08 & 0,886 & $358,3^{*}$ & 117,6 & 0,915 & 1404,8 & 830,4 \\
P09 & 0,772 & 15,9 & 106,2 & 0,567 & 142,1 & 777,7 \\
P03 & 0,784 & 62,3 & 107,8 & 1,154 & $4.955,2$ & 738,3 \\
P07 & 0,537 & 66,0 & 105,1 & 0,727 & -3193 & 628,9 \\
P02 & 0,937 & $-77,1$ & 124,0 & $1,514 *$ & $-911,9$ & 788,9 \\
P11 & 0,979 & 184 & 124,7 & 0,753 & $3.809,9$ & 763,2 \\
P05 & 0,913 & $-123,5$ & 104,0 & 1,052 & $5.993,2$ & 818,9 \\
P06 & 0,859 & $331,9 *$ & 116,3 & 1,109 & $7.606,5$ & 795,4 \\
P04 & 0,761 & $-29,8$ & 108,8 & 1,124 & $3.473,3$ & 698,4 \\
P12 & 1,729 & 120,2 & 113,5 & 1,070 & $-2.306,6$ & 732,2 \\
P10 & 1,326 & $-30,3$ & 113,8 & 1,051 & $6.517,1$ & 745,6 \\
P01 & 0,291 & $-38,6$ & 111,2 & 1,253 & $19.914,2 * *$ & 749,5 \\
H02 & 1,186 & $355,4 *$ & 130,5 & 0,594 & $8.268,7$ & 731,4 \\
H01 & $2,184 *$ & $-9,3$ & 142,4 & 1,202 & $22.321,4 * *$ & 809,1 \\
T02 & 0,903 & 150,2 & 165,4 & 0,878 & $12.027,1$ & 801,1 \\
T01 & 0,952 & 81,5 & 95,95 & 1,038 & $3.853,6$ & 707,9 \\
Média & - & - & 117,96 & - & - & 757,30 \\
\hline
\end{tabular}

**, * Significativo pelo teste t a 1 e $5 \%$, respectivamente. Grãos = Produção de grãos, em g planta ${ }^{-1}$; Massa Verde $=$ Produção de massa verde total de planta, em g planta ${ }^{-1}$ 
$\mathrm{Na}$ massa verde, o genótipo P02 apresentou coeficiente de regressão superior à unidade $(\beta>1)$, desvio da regressão não significativo e produção acima da média (788,90 g planta $^{-1}$ ) (Tabela 2), o que demonstra adaptação aos ambientes favoráveis, previsibilidade de comportamento (SCAPIM et al., 2010) e preferência de escolha em ambientes favoráveis (SILVA; DURATE, 2006). Cabe ressaltar, que na produção de grãos o genótipo P02 foi adequado tanto para ambientes favoráveis e desfavoráveis, o que pode representar que este genótipo apresentou maior resposta à melhoria do ambiente na massa verde.

Os outros genótipos avaliados apresentaram coeficiente de regressão linear igual à unidade $(\beta=1)$, indicando a adaptação em ambos os ambientes (SCAPIM et al., 2010), com os genótipos P08, P09, P11, P05, P06 e T02 apresentando desvio de regressão não significativo com massa verde acima de média $\left(830,4 ; 777,0 ; 763,0 ; 818,0 ; 795,0 ; 801,1\right.$ g planta $^{-1}$, respectivamente), os quais podem ter preferência de escolha quando não se dispõe de genótipos específicos para cada situação, visando a produção de massa verde. Os genótipos P11 e T02 apresentaram os mesmos resultados na produção de grãos, indicando que estes foram adaptados, previsíveis e produtivos em ambas as características.

Estes dados, ainda, podem indicar tendência de maior adaptação e previsibilidade das populações avaliadas na massa verde em relação à produção de grãos frente os híbridos avaliados, pois, na análise desta última característica somente duas populações foram consideradas como adequadas, a ambos os ambientes, enquanto que, na produção de massa verde, foram seis, uma para ambientes favoráveis e, cinco para ambos os ambientes.

\section{Tendência da Finalidade Produtiva}

Importante ressaltar que com relação à caracterização do genótipo voltado para silagem, a massa verde juntamente produção de grãos satisfatória são características iniciais de um genótipo (JAREMTCHUK et al., 2005; MENDES et al., 2008), o qual preferencialmente, ainda, deve apresentar maior proporção de folhas e menor de caule, porte alto (CABRALES; MONTOYA; RIVERA, 2007), boa digestibilidade (MENDES et al., 2008), alto teor e produção de matéria seca (FERRARI JÚNIOR, et $a l, 2005)$.

Como a maioria dos genótipos disponíveis no Brasil é voltada para a produção de grãos (CENTRO NACIONAL DE PESQUISA DE MILHO E SORGO, 2011), a distinção da tendência da finalidade produtiva
(TFP) entre grãos e massa verde, visualizada na Figura 1, pode trazer benefícios ao sistema produtivo, visto que o desenvolvimento de materiais específicos quanto à finalidade pode diminuir riscos na produção (MORENO-GONZÁLEZ et al., 2000), e também que a mesma (a TFP presente na Figura 1) tenta aliar no genótipo para massa verde, a produção de grãos.

Para esta distinção da TFP, primeiramente os genótipos são divididos em dois grupos, abaixo e acima da unidade no gráfico 1a (Figura 1), em que no primeiro caso pode indicar preferência pela massa verde e, no segundo, produção de grãos. Posteriormente, as respostas dos genótipos nos gráficos 1b, 1c, 1d e 1e (Figura 1) confirmam a TFP do genótipo, em que para massa verde são aqueles que, apresentam valores do gráfico $1 \mathrm{~b}$ maiores ou iguais aos do gráfico 1d (gráficos relacionados às respostas dos genótipos quanto à produção de grãos Figura 1) e também, valores do gráfico 1c maiores aos do gráfico 1e (gráficos relacionados às respostas dos genótipos quanto à massa verde - Figura 1); e para a produção grãos, apresentar aumento do valor entre os gráficos 1d e 1b (Figura 1).

Os genótipos P02, P06 e P07 foram os que apresentaram TFP para massa verde (Figura 1), com valores dos gráficos $1 \mathrm{~d} / 1 \mathrm{~b}$ de $0,93 / 0,98$ (P02), 0,85/0,85 (P06), 0,88/0,88 (P07) e, dos gráficos 1e/1c de 1,51/1,57 (P02), 1,10/1,16 (P06) e 0,91/1,03 (P07). Cabe lembrar que estes genótipos, na densidade de plantio dos experimentos, apresentaram produção estimada em $40 \mathrm{t} \mathrm{ha}^{-1}$ de massa verde (Tabela 2), estando numa posição intermediária entre os valores de produção com viabilidade econômica (30 $\mathrm{t} \mathrm{ha}^{-1}$, segundo Valente et al., 1991) e do considerado como ótimo (50 t ha-1, segundo Bates , 2009).

Os genótipos P11, T02, H02 e H01 foram os que apresentaram TFP para grãos, com valores dos gráficos 1d/1b de 0,97/1,03 (P11), 0,90/1,26 (T02), 1,18/1,31 (H02) e 2,18/2,63 (H01). O genótipo T02 correspondeu a sua recomendação de dupla finalidade, apresentando aumento dos valores tanto entre os gráficos $1 \mathrm{~d} / 1 \mathrm{~b}$ e $1 \mathrm{e} / 1 \mathrm{c}$, no entanto, como a sua resposta para grãos foi superior a massa verde (gráfico 1a), a sua TFP seria preferencialmente para grãos, em função da utilização de genótipos de milho com dupla aptidão, que pode acarretar em várias situações, por exemplo, produção de silagem visando fornecimento de alimento para produção pecuária que não é realizada, elevando os custos de produção ou redução de produtividade pecuária. 
Figura 1 - Tendência da finalidade produtiva de genótipos de milho para massa verde ou Grãos (Gráfico 'a'), Coeficiente de Regressão Linear (Gráficos 'd' e 'e') e produto deste com a Produção Relativa (Gráficos 'b' e 'c') de grãos e massa verde, de 16 genótipos de milho avaliados em oitos experimentos na região Centro-Sul do Tocantins

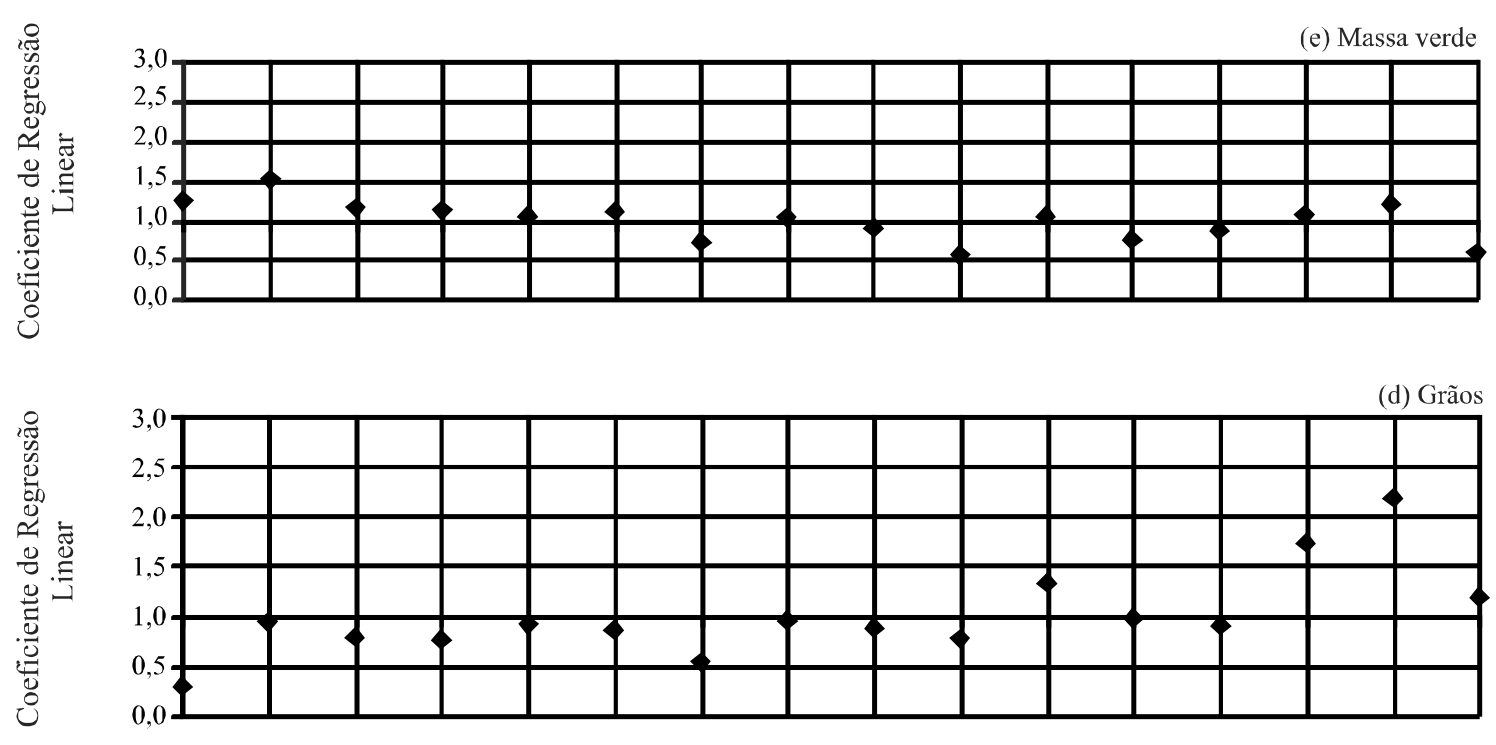

(c) Massa verde

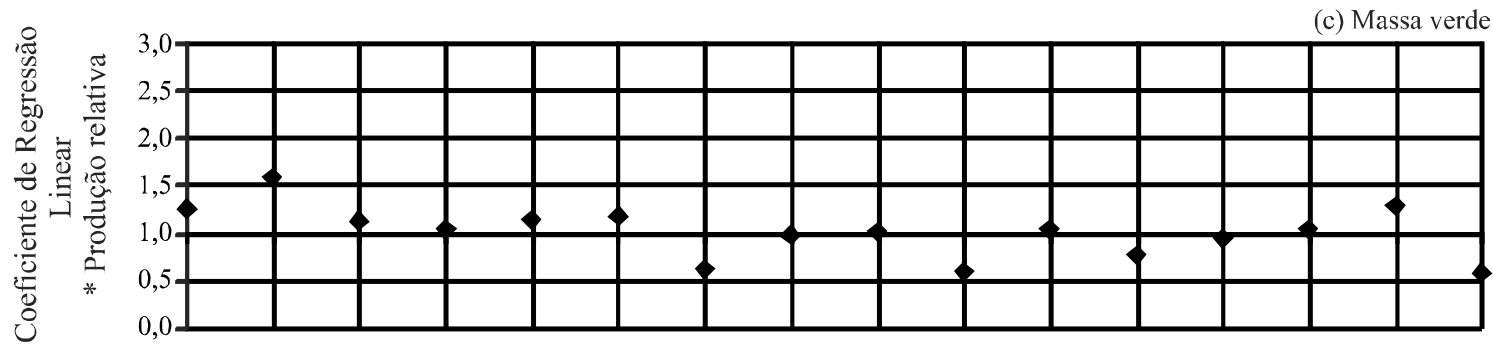

(b) Grãos
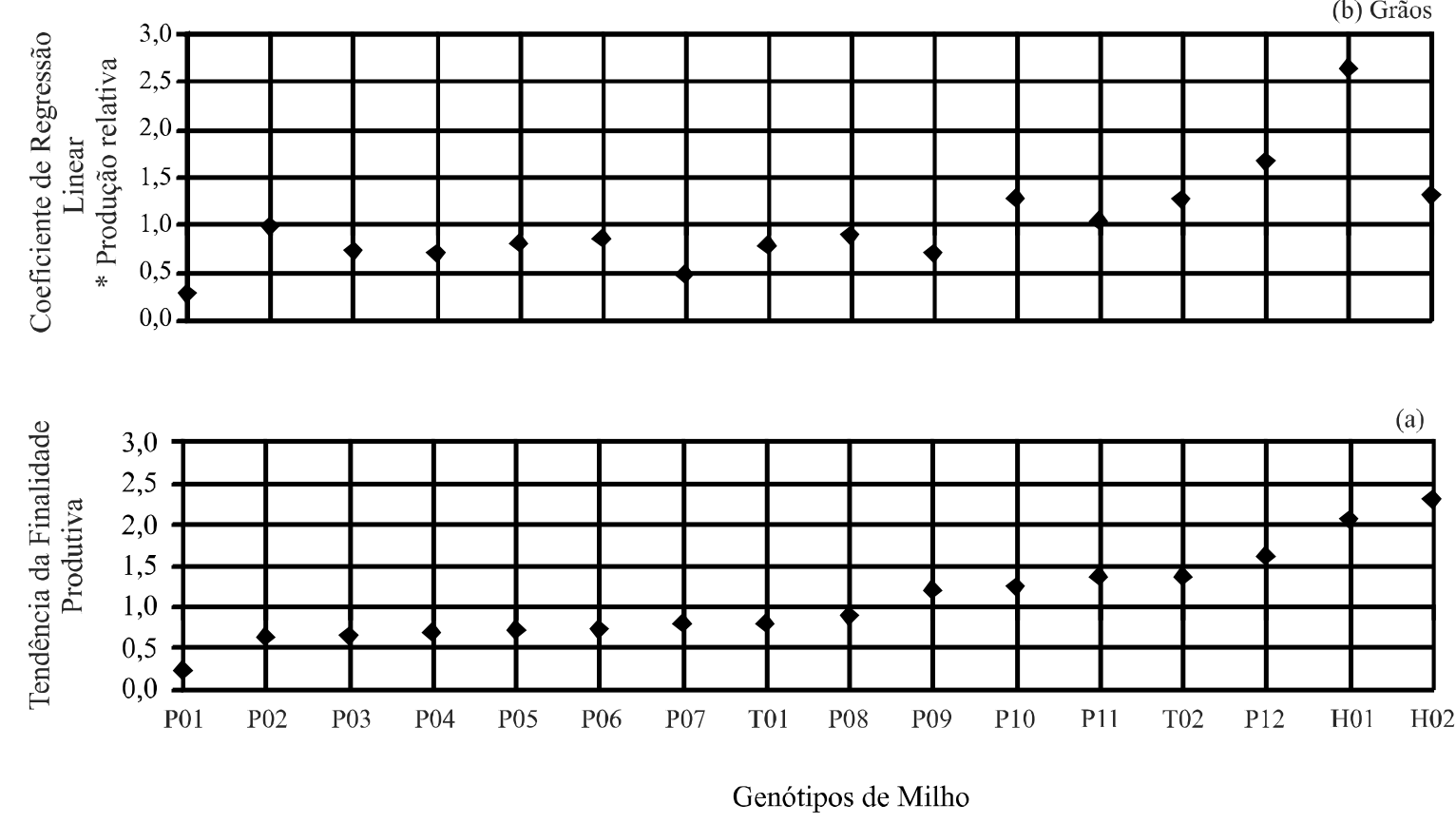


\section{CONCLUSÕES}

1.O genótipo H01 foi adequado em ambientes favoráveis e, os genótipos P02, P11 e T02 em ambos os ambientes, na produção de grãos;

2.Os genótipos P08, P09, P11, P05, P06 e T02 foram adequados em ambos os ambientes quanto à produção de massa verde total da planta, o genótipo P02, para ambientes favoráveis;

3.Os genótipos P02, P06 e P07 apresentaram tendência da finalidade produtiva para produção de massa verde total da planta e, os genótipos P11, T02, H02 e H01 para produção de grãos.

\section{REFERÊNCIAS}

BATES, G. Corn Silage. Agricultural Extension Service University of Tennesse. 2009. Disponível em: <http://extension. missouri.edu/p/G4590>. Acesso em: 20 nov. 2011.

CABRALES, R.; MONTOYA, R.; RIVERA, J. Evalución agronómica de 25 genótipos de maíz (Zea maiz) con fines forrajeiros en el valle del sinú medio. Revista MVZ, v. 12, n. 2, 2007.

CENTRO NACIONAL DE PESQUISA DE MILHO E SORGO. Milho - Cultivares para safra 2011/2012. Disponível em: <http://www.cnpms.embrapa.br/milho/cultivares/index. php>. Acesso em: 01 out. 2011.

EBERHART, S. A.; RUSSEL, W. A. Stability parameters for comparing varieties. Crop Science, v. 6. n. 1, p. 36-40, 1966.

FANCELLI, A. L.; DOURADO-NETO, D. Produção de milho. Guaíba: Agropecuária, 2000. 360 p.

FARIA, V. R. et al. Adaptabilidade e estabilidade de populações de milho-pipoca relacionadas por ciclos de seleção. Pesquisa Agropecuária Brasileira, v. 45, n. 12, p. 1396-1403, 2010.

FERRARI JÚNIOR, E. et al. Características agronômicas, composição química e qualidade de silagens de oito cultivares de milho. Boletim da Indústria Animal, v. 62, n. 1, p. 1927,2005 .

FERREIRA, D. F. Estabilidade. Versão 3.0 para Windows. Viçosa-MG: Universidade Federal de Viçosa, 1998.

JAREMTCHUK, A. R. et al. Características agronômica e bromatológicas de vinte genótipos de milho (Zea mays L.) para silagem na região leste paranaense. Acta Scientiarum. Animal Sciences, v. 27, n. 2, p. 181-188, 2005.

MENDES, M. C. et al. Avaliação de híbridos de milho obtidos do cruzamento entre linhagens com diferentes níveis de degrabilidade de matéria seca. Bragantia, v. 67, n. 2, p. 285-297, 2008.
MORENO-GONZÁLEZ, J. et al. Breeding potential of european flint and U.S. corn belt dent maize populations for forage use. Crop Science, v. 40, n. 6, p. 1588-1595, 2000.

OLIVEIRA, G. V. et al. Adaptabilidade e estabilidade de linhagens de feijão comum em Minas Gerais. Pesquisa agropecuária brasileira, v. 41, n. 2, p. 257-265, 2006.

PARIZ, C. M. et al. Desempenhos técnicos e econômicos da consorciação de milho com forrageiras dos gêneros Panicum e Brachiaria em sistema de integração lavoura-pecuária. Pesquisa agropecuária tropical, v. 39, n. 4, p. 360-370, 2009.

PELUZIO, J. M. et al. Comportamento de cultivares de soja no sul do estado do Tocantins. Bioscience Journal, v. 21, n. 3, p. 113-117, 2005.

RIOS, S. A. et al. Adaptability and stability of caretenoids in maize cultivars. Crop Breeding and Applied Biotechnology, v. 9 , n. 4, p. 313-319, 2009.

SANDOYA, G et al. Effects of selection for resistance to Sesamia nonagrioides on maize yield, performance and stability under infestation with Sesamia nonagrioides and Ostrinia nubilalis in Spain. Annals of Applied Biology, v. 156, n. 3, p. 377-386, 2010.

SANTOS, R. D. et al. Características agronômicas de variedades de milho para produção de silagem. Acta Scientiarum, Animal Sciences, v. 32, n. 4, p. 367-373, 2010 .

SCAPIM, C. A. et al. Yield stability in maize (Zea mays L.) and correlations among the parameters of the Eberhart and Russell, Lin and Binns and Huehn models. Genetics and Molecular Biology, v. 23, n. 2, p. 387-393, 2000.

SCAPIM, C. A. et al. Correlations between the stability and adaptability statistics of popcorn cultivars. Euphytica, v. 174, n. 2, p. 174-209, 2010.

SCHAEFER, C. M.; SHEAFFER, C. C.; BERNADO, R. Breeding potential of semidwarf corn for grain and forage in the northern U.S. corn belt. Crop Science, v. 51, n. 4, p. 16371645, 2011.

SILVA, A. F. Manejo Cultural do Milho Forrageiro. In: EMPRESA BRASILEIRA DE PESQUISA AGROPECUÁRIA. Centro Nacional de Pesquisa de Milho e Sorgo. Milho para silagem: tecnologias, sistemas e custo de produção. Sete Lagoas: EMBRAPA - CNPMS, 1991. p. 9-27. (Circular Técnica, 14).

SILVA, W. C. J.; DUARTE, J. B. Métodos estatísticos para estudo da adaptabilidade e estabilidade fenotípica em soja. Pesquisa Agropecuária Brasileira, v. 41, n. 1, p. 23-30, 2006.

VALENTE, J. O. Introdução. In: EMPRESA BRASILEIRA DE PESQUISA AGROPECUÁRIA. Centro Nacional de Pesquisa de Milho e Sorgo. Milho para silagem: tecnologias, sistemas e custo de produção. Sete Lagoas: EMBRAPA CNPMS, 1991. p. 5-7. (Circular Técnica, 14). 